\title{
Synthesis of graft copolymers of acrylamide for locust bean gum using microwave energy: swelling behavior, flocculation characteristics and acute toxicity study
}

\author{
Tapan Kumar Giri', Sanjeet Pure² and Dulal Krishna Tripathi²
}

${ }^{1}$ NSHM College of Pharmaceutical Technology, Department of Pharmaceutics, NSHM Knowledge Campus, Kolkata Group of Institutions, Under West Bengal University of Technology, Kolkata, West Bengal, India

${ }^{2}$ Rungta College of Pharmaceutical Sciences and Research, Under Swami Vivekananda Technical University, Kohka Road, Kurud, Bhilai, Chhattisgarh, India

*tapanju01@rediffmail.com

\begin{abstract}
The graft copolymer of locust bean gum (LBG) and acrylamide has been synthesized by microwave assisted method using potassium persulphate (KPS) as an initiator in aqueous medium. Different reaction parameters such as time, initiator concentration, monomer concentration, polymer concentration, and microwave power were studied to get maximum graft copolymer. The grafted copolymer was characterized by Fourier transform infrared spectroscopy (FT-IR), scanning electron microscopy (SEM), X-ray diffraction (XRD), and differential scanning calorimetry (DSC). The graft copolymer exhibited $\mathrm{pH}$ switching on-off behavior depending on the $\mathrm{pH}$ of the external medium. Flocculation capacity of LBG and LBG-graft-polyacrylamide for both coking and non-coking coals has been studied. Results indicated that the graft copolymer exhibited good flocculation properties compared to native polymer. The graft copolymer was non-toxic in the acute toxicity study, since the acute single dose did not cause any toxic signs, or symptoms. All mice treated with the graft copolymer survived beyond the 14 days of observation period.
\end{abstract}

Keywords: biopolymers, grafting reaction, microwave synthesis, flocculation, swelling.

\section{Introduction}

Locust bean gum is a white to yellowish powder obtained by crushing the endosperm of the seeds of the fruit pod of carob tree, a large leguminous evergreen found in Mediterranean regions ${ }^{[1]}$. It is a linear polysaccharide consisting of $\beta$-(1,4)-D-mannose units and every fourth mannose units is substituted with a small side chain consisting of a 1,6 linked $\alpha$-galactose sugar ${ }^{[2]}$. The ratio of D-galactose to D-mannose differs due to the varying origins of the gum materials and growth conditions of the plant during production. The galactomannans are the main constituent of LBG (80-91\%), with protein accounting for 5-6\%, $1-4 \%$ cellulose, and $1 \%$ of ashes ${ }^{[3]}$. The physico-chemical properties of galactomannan are strongly influenced by the galactose content and the distribution of the galactose units along the main chain. It is widely used in the food industry as stabilizer and viscosity modifier, as well as in the textile industry by its film-forming properties ${ }^{[4]}$. It has found increasing applications in the drug delivery systems and tissue engineering purpose $\mathrm{e}^{[5-7]}$. Although, LBG has wide range of uses and applications, it suffers from certain drawback like uncontrolled hydration, microbial contamination and drop in viscosity.

Presently a trend has come to modify polysaccharides in order to alter their physico-chemical properties. Graft copolymerization of synthetic polymers onto polysaccharide backbone offers one of the best ways to use polysaccharides for a diversity of purposes ${ }^{[8]}$. Grafting provides a appropriate method for tailoring material properties to specific end uses. A graft copolymer is a macromolecular chain with one or more species of block attached to the main chain as side chains ${ }^{[9]}$. The process of graft copolymer synthesis starts with a performed polymer (polysaccharide in this case). An external agent is used to produce free radical sites on this performed polymer. Once the free radical sites are formed on the polymer backbone, the monomer can get added up through the chain propagation step, leading to the formation of grafted chains. The best method of graft copolymer synthesis is by use of microwave radiation to produce the free radical sites on the backbone polymer. Owing to a number of characteristic advantages such as shorter radiation times, higher yields, limited generation of byproducts and the relatively simple scale-up without unfavorable effects, microwave based synthesis has progressively become an interesting tool ${ }^{[10]}$. The most frequently used method is to perform grafting reactions under microwave irradiation in the presence of a free radical initiator (microwave assisted grafting ${ }^{[11]}$. The lesser known method involves the use of microwave radiation in the absence of any free radical initiator (microwave initiated grafting) $)^{[12]}$. Though both the aforementioned grafting methods lead to significant and quick grafting of polysaccharides, grafting yields are generally higher in the microwave-assisted grafting ${ }^{[13]}$.

Reports of grafting of LBG are scantily available so, in the light of versatile applications of LBG, this work has been carried out with aim to tailor LBG based hybrid materials by grafting polyacrylamide using KPS. The optimum grafting conditions have been obtained, and various studies have been carried on swelling capacity, flocculation ability, and acute toxicity. 


\section{Materials and Methods}

\subsection{Materials}

LBG(Purity 99\%) was supplied by Victory Essence Mart, Bangalore, India. AAm(Purity 99\%), KPS(Purity 98\%), and methanol(Purity 99.8\%) were purchased from Loba Chemie, Mumbai, India. Double distilled water was prepared in the laboratory. For the flocculation, coking and non coking coals were received from steel plant Bhilai, India. All other reagents were of analytical grades and used as received.

\subsection{Microwave assisted synthesis of polyacrylamide grafted $L B G$}

Polyacrylamide grafted LBG was synthesized by microwave assisted method (using microwave energy as well as KPS as initiator to generate free radical sites). $0.125 \mathrm{~g}$ to $0.5 \mathrm{~g}$ of LBG was dissolved in $25 \mathrm{ml}$ distilled water. $0.5 \mathrm{~g}$ to $3 \mathrm{~g}$ of acrylamide was dissolved in $5 \mathrm{ml}$ of water and added to the above solution. $1 \mathrm{mg}$ to $400 \mathrm{mg}$ of KPS was dissolved in $5 \mathrm{ml}$ of water and also added to above dispersion. They were mixed well and were transferred to the reaction vessel ( $500 \mathrm{ml}$ borosil beaker). The solution obtained was irradiated by microwave in domestic microwave oven (20STP21,
MIRC Electronics Ltd., Mumbai, India) for different times and different powers to prepare series of graft copolymer. Once the microwave irradiation for the intended amount of time was complete, the gel like mass left in the reaction vessel was cooled at room temperature for $2 \mathrm{hr}$ and poured into excess of methanol. The precipitated grafted polymer was dried and then extracted using a formamide-acetic acid mixture (1:1 by volume) to remove the homopolymer ${ }^{[14]}$. Then the product was washed with methanol: water $(80: 20)$ mixture and filtered. The final graft copolymer was then dried to a constant weight at $45^{\circ} \mathrm{C}$. The grafting conditions are given in Table 1 . The percentage grafting $(\% \mathrm{G})$ and percentage grafting efficiency $(\% \mathrm{GE})$ were calculated using following equations ${ }^{[14]}$ :

$$
\begin{aligned}
& \% G=\frac{\left(w_{1}-w_{0}\right)}{w_{0}} \times 100 \\
& \% G E=\frac{\left(w_{1}-w_{0}\right)}{w_{2}} \times 100
\end{aligned}
$$

Where $\mathrm{w}_{0}=$ weight of polysaccharide taken $\mathrm{w}_{1}=$ weight of graft copolymer $\mathrm{w}_{2}=$ weight of acrylamide taken

\begin{tabular}{|c|c|c|c|c|c|}
\hline \multirow{2}{*}{ Optimization parameters } & \multicolumn{5}{|c|}{ Reaction Conditions } \\
\hline & Time(s) & Power(W) & KPS(mg) & $\operatorname{AAm}(g)$ & LBG(g) \\
\hline \multirow[t]{9}{*}{ Effect of initiator concentration } & 120 & 800 & 1 & 1 & 0.25 \\
\hline & 120 & 800 & 5 & 1 & 0.25 \\
\hline & 120 & 800 & 10 & 1 & 0.25 \\
\hline & 120 & 800 & 20 & 1 & 0.25 \\
\hline & 120 & 800 & 40 & 1 & 0.25 \\
\hline & 120 & 800 & 100 & 1 & 0.25 \\
\hline & 120 & 800 & 200 & 1 & 0.25 \\
\hline & 120 & 800 & 300 & 1 & 0.25 \\
\hline & 120 & 800 & 400 & 1 & 0.25 \\
\hline \multirow[t]{7}{*}{ Effect of monomer concentration } & 120 & 800 & 200 & 0.5 & 0.25 \\
\hline & 120 & 800 & 200 & 0.75 & 0.25 \\
\hline & 120 & 800 & 200 & 1 & 0.25 \\
\hline & 120 & 800 & 200 & 1.5 & 0.25 \\
\hline & 120 & 800 & 200 & 2 & 0.25 \\
\hline & 120 & 800 & 200 & 2.5 & 0.25 \\
\hline & 120 & 800 & 200 & 3 & 0.25 \\
\hline \multirow[t]{6}{*}{ Effect of microwave irradiation time } & 30 & 800 & 200 & 2.5 & 0.25 \\
\hline & 60 & 800 & 200 & 2.5 & 0.25 \\
\hline & 90 & 800 & 200 & 2.5 & 0.25 \\
\hline & 120 & 800 & 200 & 2.5 & 0.25 \\
\hline & 150 & 800 & 200 & 2.5 & 0.25 \\
\hline & 180 & 800 & 200 & 2.5 & 0.25 \\
\hline \multirow[t]{5}{*}{ Effect of microwave power } & 120 & 480 & 200 & 2.5 & 0.25 \\
\hline & 120 & 560 & 200 & 2.5 & 0.25 \\
\hline & 120 & 640 & 200 & 2.5 & 0.25 \\
\hline & 120 & 720 & 200 & 2.5 & 0.25 \\
\hline & 120 & 800 & 200 & 2.5 & 0.25 \\
\hline \multirow[t]{5}{*}{ Effect of polymer concentration } & 120 & 800 & 200 & 2.5 & 0.125 \\
\hline & 120 & 800 & 200 & 2.5 & 0.1875 \\
\hline & 120 & 800 & 200 & 2.5 & 0.25 \\
\hline & 120 & 800 & 200 & 2.5 & 0.375 \\
\hline & 120 & 800 & 200 & 2.5 & 0.5 \\
\hline
\end{tabular}

Table 1. Synthesis details of the graft copolymers. 


\subsection{Fourier transform infrared spectroscopy}

Infrared spectra were recorded on Fourier-transform infrared (FT-IR) spectrometer (Prestige-21, Shimatzu, Japan) in the range of $4000-400 \mathrm{~cm}^{-1}$.

\subsection{X-ray diffraction (XRD)}

$\mathrm{X}$-ray diffractogram of samples were recorded employing $\mathrm{X}$-ray diffractometer (Ultima-III, Rigaku, Japan) using copper target slit $10 \mathrm{~mm}$ in the differential angle range of $0-60^{\circ}(2 \theta)$.

\subsection{Scanning electron microscopy}

The surface morphologies of the particles were examined by a scanning electron microscope (JEOL, JSM6360, UK). The photomicrograph of sample was taken at an accelerating voltage at $17 \mathrm{kV}$ at different magnifications.

\subsection{Swelling studies}

$200 \mathrm{mg}$ of sample was kept in swelling medium for $3 \mathrm{~h}$ to study the swelling behavior. After $3 \mathrm{~h}$ the graft copolymer sample was taken out and the surface medium of swollen graft copolymer was removed by softly pressing the sample in between the folds of filter paper. After this the sample was weighed and increase in weight was recorded.

To investigate the swelling behaviors of the samples at various $\mathrm{pHs}$, individual solutions were prepared by diluting $\mathrm{NaOH}(\mathrm{pH}=12.0)$ and $\mathrm{HCl}(\mathrm{pH}=2.0)$ solutions, respectively. To study the $\mathrm{pH}$-responsiveness of the sample buffer solution with $\mathrm{pH} 2$ and 9 were used. The swelling ratio was calculated as follows ${ }^{[15]}$ : Swelling ratio $=($ weight of swollen sample-weight of dry sample)/weight of dry sample.

\subsection{Flocculation studies}

Flocculation experiments were carried out using a USP II dissolution rest test apparatus (Paddle type) (TDT-08L, Electro lab, Mumbai, India). Flocculation experiments were carried out with suspensions containing $1 \mathrm{wt} \%$ fine coal particles in order to evaluate the efficiency of graft copolymer for the treatment of coal mine waste water. Dissolution medium was prepared by dissolving $5 \mathrm{gm}$ of fine coal particles in $500 \mathrm{ml}$ of double distilled water. $500 \mathrm{ml}$ of $1 \mathrm{wt} \%$ coal suspension was taken in dissolution rate test apparatus. Next, 2-10 ppm of polyacrylamide grafted LBG(Graft copolymer was obtained by using $20 \times 10^{-3} \mathrm{~mol} / \mathrm{L}$ KPS, $71.42 \mathrm{~g} / \mathrm{L}$ AAm, 7.14 g/L LBG, $800 \mathrm{~W}$ microwave power and $120 \mathrm{~min}$ exposure time) as flocculant was added to the mixture and it then underwent slow mixing at $50 \mathrm{rpm}$ for $30 \mathrm{~min}$. The mixture was then allowed to stand for $5 \mathrm{~min}$, to settle. $10 \mathrm{ml}$ of supernatant was withdrawn with a syringe at $1 \mathrm{~cm}$ from the surface and its turbidity was measured using a digital nephelometer (Model-341, EI Lab, Himachal Pradesh, India) to express the turbidity in nephelometric unit (NTU).

\subsection{Acute toxicity study in mice}

Mice of female sexes, aged 12 weeks, and weighing 25-30 g were used. The animals were acclimatized to laboratory conditions for 7 days prior to the experiments. The mice were maintained at a room temperature of $22 \pm 2^{\circ} \mathrm{C}$, with $40-70 \%$ relative humidity and a $12 \mathrm{~h}$ light/ dark cycle. During acclimatization, the animals were housed in polycarbonate cages, with free access to normal diet and tap water ad libitum. All procedures in this study were performed according to the Animal Ethics Committee of Rungta College of Pharmaceutical Sciences and Research, Bhilai, India (CPCSEA approval No: 1189/RCPSR/12/07/ $\mathrm{PO} / \mathrm{a} / 08 /$ CPCSEA). A single dose of $2000 \mathrm{mg} / \mathrm{Kg}$ body weight of graft copolymer was administered by gavages using a stomach tube to the first animal. The same dose was administered to the remaining four animals after survival of the first animal. Observations were made and recorded systematically 1,2,3 and $4 \mathrm{~h}$ after administration of graft copolymer, and daily thereafter for a total of 14 days. The mortality rate was evaluated by visible observation and reported accordingly.

\section{Results and Discussion}

Graft copolymers were synthesized by grafting acrylamide onto LBG by a radical polymerization using KPS as the initiator. The persulphate initiator is decomposed under microwave to generate sulphate ion radicals. Then the hydrogen radical is abstracted from the hydroxyl group of the polysaccharide to form alkoxy radicals on the substrate. The scheme of free radical reaction is given in Scheme 1.

\subsection{Characterization of graft copolymer}

In the case of acrylamide (Figure 1a), a broad absorption band at $3352.52 \mathrm{~cm}^{-1}$ is for the $\mathrm{NH}$ stretching frequency of the $\mathrm{NH}_{2}$ group. Two strong bands around $1674.21 \mathrm{~cm}^{-1}$ and $1621.49 \mathrm{~cm}^{-1}$ are due to amide I (CO stretching) and amide II (NH bending). The bands around $1429.25 \mathrm{~cm}^{-1}$ and $2812.21 \mathrm{~cm}^{-1}$ are for the $\mathrm{C}-\mathrm{N}$ and C-H stretching vibrations. It can be seen that a broad absorption band in locust bean gum (Figure 1b) at $3367.71 \mathrm{~cm}^{-1}$ is due to the stretching frequency of the $\mathrm{O}-\mathrm{H}$ groups. The bands around 1026.13 and $2887.43 \mathrm{~cm}^{-1}$ are assigned to $\mathrm{C}-\mathrm{O}$ stretching as well as $\mathrm{C}-\mathrm{H}$ stretching respectively. A band at $1386.81 \mathrm{~cm}^{-1}$ for the $\mathrm{CH}_{2}$ scissoring vibration.

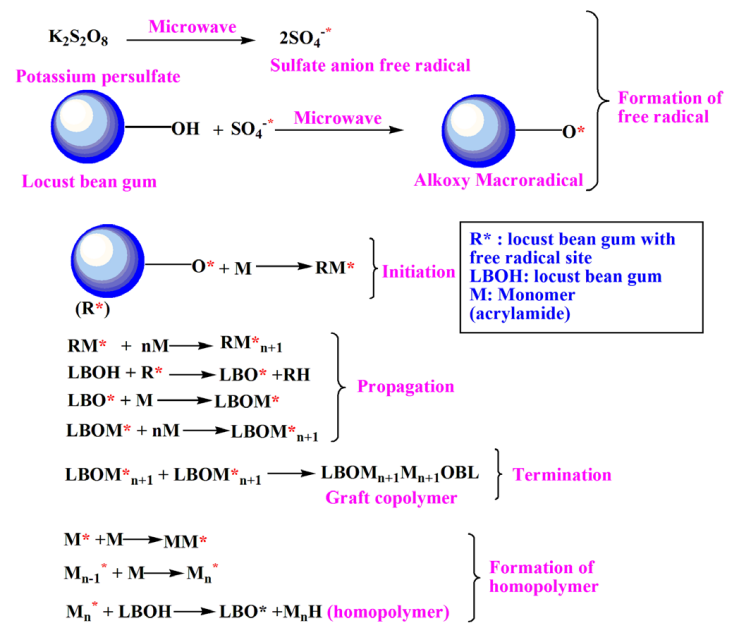

Scheme 1. Schematic representation for the synthesis of graft copolymer. 

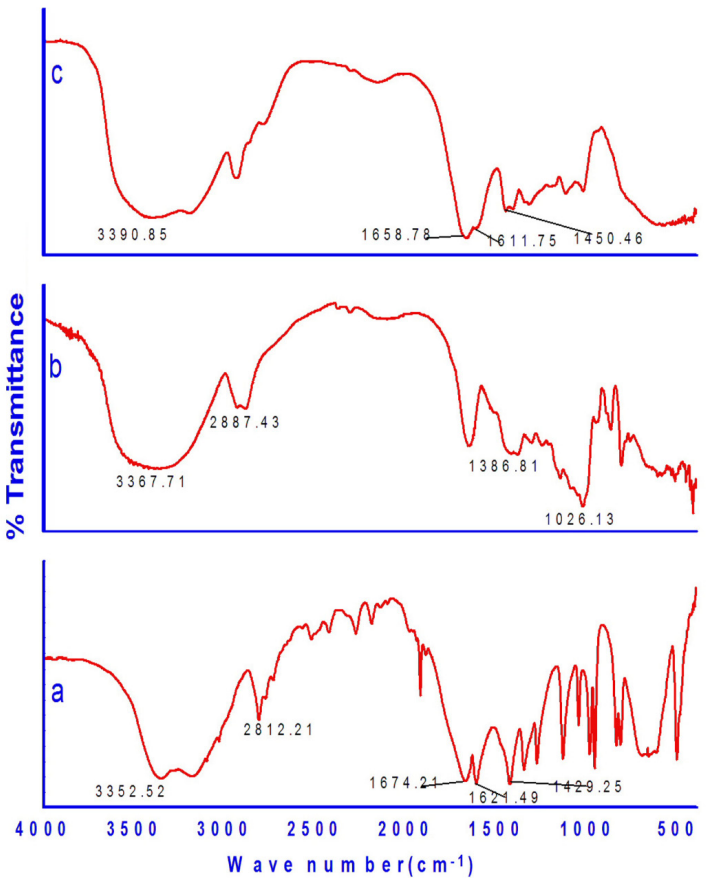

Figure 1. FTIR spectra of (a) acrylamide, (b) locust bean gum, (c) grafted copolymer(Graft copolymer was obtained by using $20 \times 10^{-3}$ $\mathrm{mol} / \mathrm{L} \mathrm{KPS}, 71.42 \mathrm{~g} / \mathrm{L}$ AAm, $7.14 \mathrm{~g} / \mathrm{L}$ LBG, $800 \mathrm{~W}$ microwave power and $120 \mathrm{~min}$ exposure time).

In acrylamide grafted locust bean gum, O-H stretching band of hydroxyl group of locust bean gum and N-H stretching band of amide group of acrylamide overlap with each other and lead to a broad band, which appear at $3390.85 \mathrm{~cm}^{-1}$ for graft copolymer (Figure 1c). The amide-I (CO stretching) occurred at $1658.78 \mathrm{~cm}^{-1}$ and amide -II (bending) occurred at $1611.75 \mathrm{~cm}^{-1}$. The $\mathrm{C}-\mathrm{N}$ stretching of acrylamide appeared at $1450.46 \mathrm{~cm}^{-1}$.

The diffractogram of acrylamide, locust bean gum, and grafted copolymer are shown in Figure 2A. In case of acrylamide, the crystalline peaks are appearing in $2 \theta$ range of $0-60^{\circ}$ (Figure $2 \mathrm{Aa}$ ). Locust bean gum showed no considerable peak of crystallinity (Figure $2 \mathrm{Ab}$ ). The graft copolymer showed amorphous structure as demonstrated by broad halo (Figure 2Ac). It is thus concluded that grafting leads to disruption in the original crystalline structure of acrylamide.

Acrylamide possess crystalline structure (Figure 2Ba). The surface of locust bean gum is fibrous in nature (Figure $2 \mathrm{Bb}$ ). Grafted copolymer shows that the grafting of acrylamide onto locust bean gum brings about the change in the shape and size of locust bean gum particle (Figure 2Bc). Further it can be observed that particles of grafted copolymer are bigger in size than ungrafted locust bean gum.

\subsection{Optimization of grafting conditions}

The optimum reaction condition was obtained by varying the concentration of initiator, monomer, polymer along with reaction time and temperature and their effect on grafting parameters have been studied.

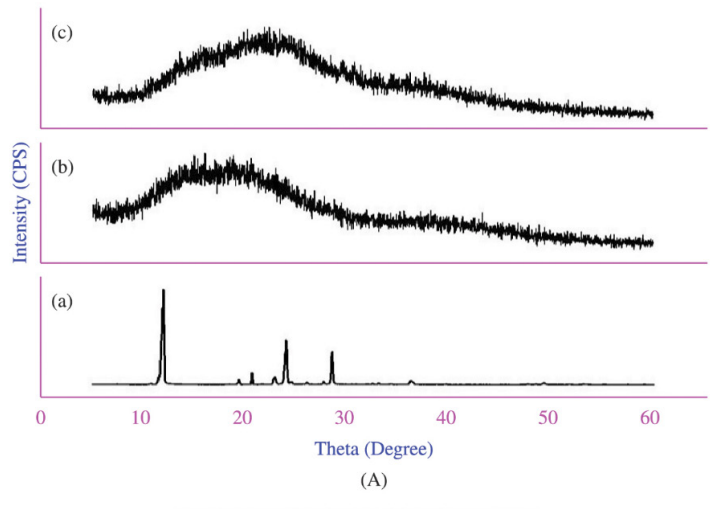

(a)

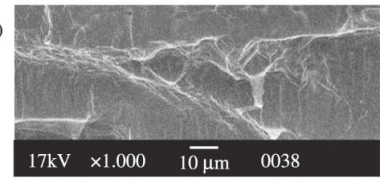

(b)

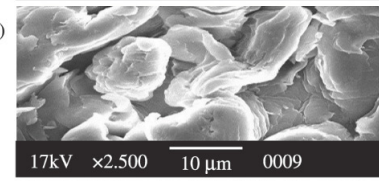

(c)

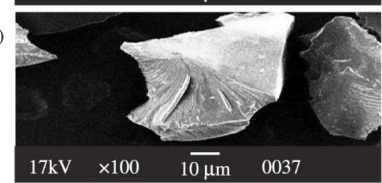

(B)

Figure 2. A. XRD spectrum of (a) acrylamide, (b) locust bean gum, (c) graft copolymer (Graft copolymer was obtained by using $20 \times 10^{-3} \mathrm{~mol} / \mathrm{L} \mathrm{KPS}, 71.42 \mathrm{~g} / \mathrm{L}$ AAm, $7.14 \mathrm{~g} / \mathrm{L} \mathrm{LBG}, 800 \mathrm{~W}$ microwave power and $120 \mathrm{~min}$ exposure time) $\mathrm{B}$. Scanning electron micrograph of a) acrylamide b) LBG c) graft copolymer(Graft copolymer was obtained by using $20 \times 10^{-3} \mathrm{~mol} / \mathrm{L}$ KPS, 71.42 $\mathrm{g} / \mathrm{L}$ AAm, $7.14 \mathrm{~g} / \mathrm{L} \mathrm{LBG}, 800 \mathrm{~W}$ microwave power and $120 \mathrm{~min}$ exposure time).

\subsection{Effect of initiator concentration}

The amount of initiator $\left(\mathrm{K}_{2} \mathrm{~S}_{2} \mathrm{O}_{8}\right)$ was varied from $0.1 \times 10^{-3}$ to $40 \times 10^{-3} \mathrm{~mol} / \mathrm{L}$ keeping other variables fixed (Figure 3a). As the concentration of initiator increases the grafting parameters first increases rapidly at lower initiator concentrations and then decreases. Initially an increase in grafting with the increase in persulphate concentration may be ascribed to the consumption of the growing monomer free radicals at the activated sites on the backbone for the grafting. However, on increasing persulphate concentration $>20 \times 10^{-3}$ $\mathrm{mol} / \mathrm{L}$, grafting decreases as homopolymer formed which compete with the grafting reaction for available monomer. Similar observations were made by other author ${ }^{[16]}$. So the optimum initiator concentration is $20 \times 10^{-3} \mathrm{~mol} / \mathrm{L}$.

\subsection{Effect of monomer concentration}

With increase in concentration of acrylamide from 14.28 to $85.71 \mathrm{~g} / \mathrm{L}, \% \mathrm{G}$ and $\%$ GE increased gradually and achieved the maximum when the concentration of acrylamide is $71.42 \mathrm{~g} / \mathrm{L}$ (Figure $3 \mathrm{~b}$ ). Afterwards, the $\% \mathrm{G}$ and $\% \mathrm{GE}$ decreased. An increase of monomer concentration leads to 


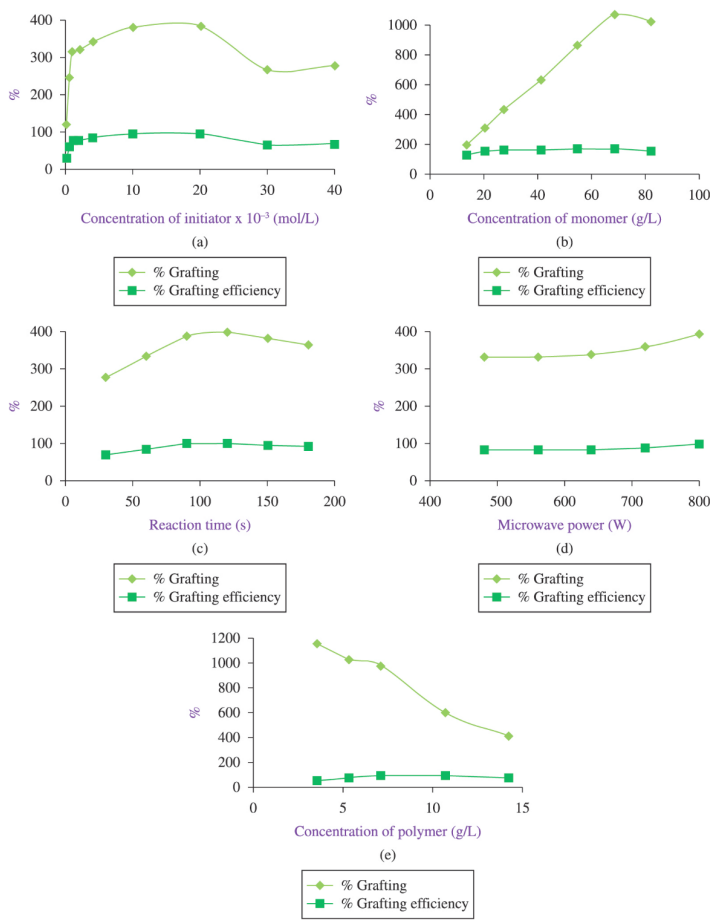

Figure 3. a) Effect of initiator concentration keeping other variables constant at $[\mathrm{LBG}]=7.14 \mathrm{~g} / \mathrm{L} ;[\mathrm{AAm}]=28.57 \mathrm{~g} / \mathrm{L}$; reaction volume $=35 \mathrm{ml}$; microwave power $=800 \mathrm{~W}$; grafting time $=120 \mathrm{~s} . \mathrm{b})$ Effect of monomer concentration keeping other variables constant at $[\mathrm{LBG}]=7.14 \mathrm{~g} / \mathrm{L} ;[\mathrm{KPS}]=20 \times 10^{-3} \mathrm{~mol} / \mathrm{L}$; reaction volume $=35 \mathrm{ml}$; microwave power $=800 \mathrm{~W}$; grafting time $=120 \mathrm{~s} . \mathrm{c})$ Effect of irradiation time keeping other variables constant at $[\mathrm{LBG}]=7.14 \mathrm{~g} / \mathrm{L} ;[\mathrm{KPS}]=20 \times 10^{-3} \mathrm{~mol} / \mathrm{L} ;[\mathrm{AAm}]=$ $71.42 \mathrm{~g} / \mathrm{L}$; reaction volume $=35 \mathrm{ml}$; microwave power $=800 \mathrm{~W} . \mathrm{d}$ ) Effect of microwave power keeping other variables constant at $[\mathrm{LBG}]=7.14 \mathrm{~g} / \mathrm{L} ;[\mathrm{KPS}]=20 \times 10^{-3} \mathrm{~mol} / \mathrm{L} ;[\mathrm{AAm}]=71.42 \mathrm{~g} / \mathrm{L}$; reaction volume $=35 \mathrm{ml}$; reaction time $=120 \mathrm{~s}$. e) Effect of LBG concentration keeping other variables constant at $[\mathrm{KPS}]=20 \times 10^{-3}$ $\mathrm{mol} / \mathrm{L} ;[\mathrm{AAm}]=71.42 \mathrm{~g} / \mathrm{L}$; reaction volume $=35 \mathrm{ml}$; reaction time $=120 \mathrm{~s} ;$ microwave power $=800 \mathrm{~W}$.

the accumulation of monomer free radicals in close proximity to the backbone and give rise to graft copolymerization. However, at higher monomer concentration, the primary radicals attacked the monomer instead of reacting with the backbone polymer. Thereby, initiating homopolymerization reaction and thus the low graft yield was observed beyond optimum monomer concentration. Similar observation was reported by other workers ${ }^{[17]}$. So the optimum monomer concentration is $71.42 \mathrm{~g} / \mathrm{L}$.

\subsection{Effect of microwave irradiation time}

The effect of exposure time was monitored by irradiating the reaction mixture for various time periods ranging from 30 to 180 s keeping the other variables fixed. The $\% \mathrm{G}$ and $\%$ GE both increased quickly up to 120 s exposure and then decreased (Figure 3c). On increasing the time period propagation of grafting chains takes place due to availability of more active species, which accounts for higher grafting. However, decrease in grafting parameters beyond optimum reaction time could be due to dominance of homopolymerization over graft copolymerization and also decomposition of the graft copolymer. Similar observation was reported by other worker $^{[18]}$. So the optimum reaction time is $120 \mathrm{~s}$.

\subsection{Effect of microwave power}

The grafting was carried out at different microwave powers ranging from 480 to $800 \mathrm{~W}$. $\% \mathrm{G}$ and $\% \mathrm{GE}$ both increases with the increasing microwave power up to $800 \mathrm{~W}$. This may be due to more availability of microwave energy at high microwave power, causing generation of more monomer and macroradicals that resulted in high percentage grafting (Figure 3d). Similar observation was made by other authors ${ }^{[19]}$. So the optimum microwave power is $800 \mathrm{~W}$.

\subsection{Effect of polymer concentration}

The effect of concentration of LBG on grafting parameters has been studied by varying the concentration of LBG from 3.57 to $14.28 \mathrm{~g} / \mathrm{L}$ (Figure $3 \mathrm{e}$ ). It was observed that the $\% \mathrm{G}$ decreased with the increased LBG concentration. The decrease in monomer/LBG ratio is responsible for the decrease in $\% \mathrm{G}$. However, $\% \mathrm{GE}$ increases up to $7.14 \mathrm{~g} / \mathrm{L}$ and thereafter declines. This could be due to availability of more grafting sites with increasing concentration of LBG. As the concentration of LBG further increases, which hinders the movement of free radicals, thereby decreasing the \% grafting efficiency. Similar observation was made by other author ${ }^{[20]}$. So the optimum LBG concentration is $7.14 \mathrm{~g} / \mathrm{L}$.

\subsection{Flocculation study}

Turbidity values of supernatant liquids have been taken as the measurement of flocculation efficiency of graft copolymer. Plots of supernatant turbidity versus polymer dosage for coking and non-coking coals are given in Figure 4. It has been found that grafted copolymer shows better performance than LBG itself. The major mechanism of flocculation by polymers is bridging ${ }^{[21]}$. The bridging takes place by adsorption of a polymer molecule at more than one site on a particle or at sites on different particles. For effective bridging to occur, the length of polymer chains should be long so that they can extend from one particle surface to another. The copolymer molecules with longer chains would be more effective than with short ones. Thus, by grafting of acrylamide onto LBG, efficient flocculants have been obtained and it could be used for the treatment of coal wastewater. The difference in turbidity value in coking coal and non-coking coal in coal suspension is due to difference in negative charge density, which is higher in non-coking coal in aqueous solution ${ }^{[22]}$.

\subsection{Swelling study}

Swelling behavior of the graft copolymer was studied at various $\mathrm{pH}$ values between 1 and 12 (Figure 5a). The dependence of the equilibrium swelling of the graft copolymer is characterized by a curve with two maxima at $\mathrm{pH} 3$ and 9. The remarkable swelling changes are due to the presence of different interacting species depending on the $\mathrm{pH}$ of swelling medium. Under acidic conditions, the swelling is controlled mainly by the amino group of polyacrylamide chain. It gets protonated and the increased charge density on the polymer should enhance the osmotic pressure inside the 


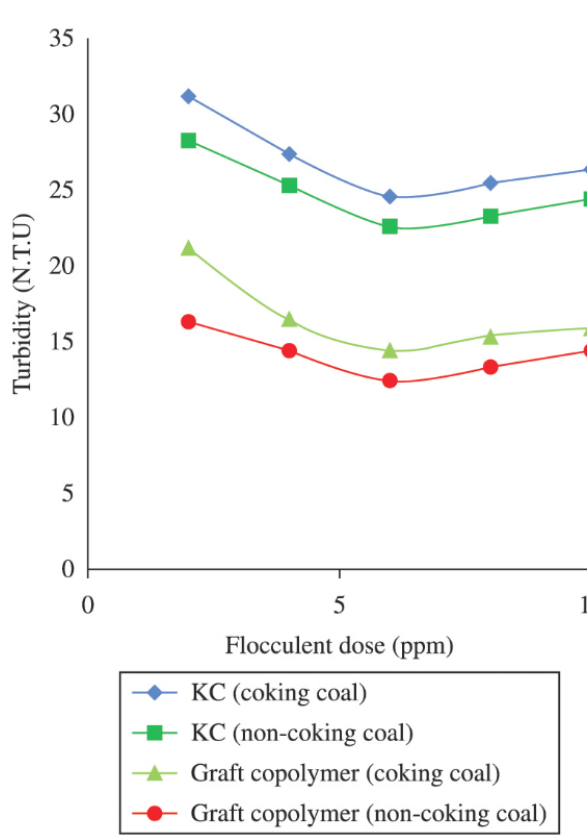

Figure 4. Effect of polymer dosage on turbidity for coking and non-coking coal.

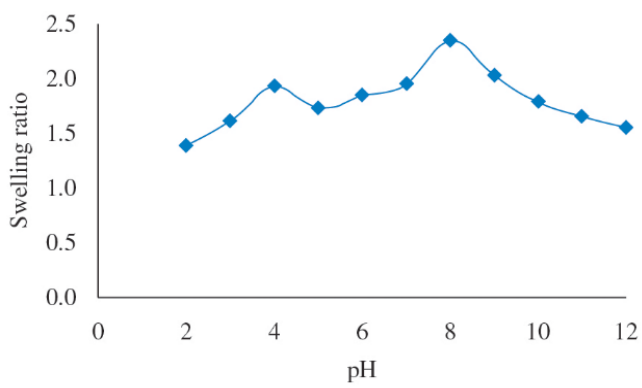

(a)

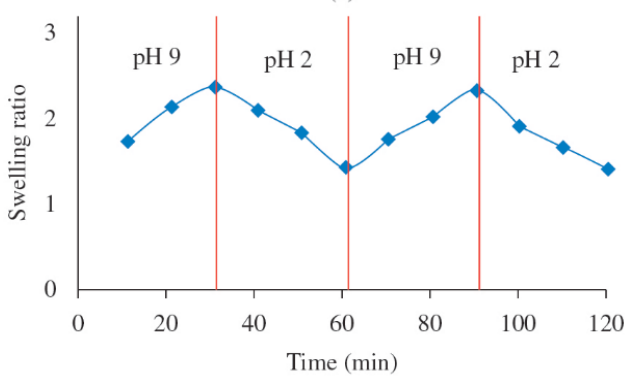

(b)

Figure 5. a) Swelling of graft copolymer in various $\mathrm{pH}$ solutions b) pulsatile swelling.

gel particles. However, under very acidic conditions $(\mathrm{pH}<3)$, a charge screening effect of the gegenion, which shields the charge of the ammonium cations and prevents an efficient repulsion. As a result a remarkable decrease in equilibrium swelling is observed. In basic medium, amide group of polysaccharide hydrolyze and converted into carboxylate ion $\left(\mathrm{COO}^{-}\right)$and resulted in the $\mathrm{COO}^{-} \mathrm{COO}^{-}$ion repulsion causes an increase in swelling ${ }^{[23]}$. Again, a screening effect of the gegenion $\left(\mathrm{H}^{+}\right)$limits the swelling at $\mathrm{pH}>9^{[24]}$.
To evaluate the re-swelling ability and the $\mathrm{pH}$ sensitivity of the graft copolymer, the samples were put in $\mathrm{pH} 9$ solutions, and then transferred to $\mathrm{pH} 2$ solutions. At $\mathrm{pH} 9$, the graft copolymer swells due to repulsive electrostatic forces, while at $\mathrm{pH} 2$, it shrinks due to charge screening effect of the gegenion (Figure 5b). This swelling-deswelling behavior of the graft copolymer makes them suitable candidates for designing drug delivery systems.

\subsection{Acute toxicity study}

Acute toxicity of graft copolymer was evaluated in female mice. All animals were observed individually for clinical signs of toxicity immediately after dosing and at 1, 2, 4, 8, 16 , and $24 \mathrm{~h}$ after dosing. The number of survivors were noted after $24 \mathrm{~h}$ and then maintained for a further 14 days with a once daily observation. None of the mice lost body weight after dosing with graft copolymer (data not shown). Following acute oral administration of graft copolymer at $2000 \mathrm{mg} / \mathrm{Kg}$, animals did not show any behavioral changes. All animals treated with graft copolymer survived beyond the 14 days observation period. Therefore, the $\mathrm{LD}_{50}$ value for oral administration of the graft copolymer in mice exceeds $2000 \mathrm{mg} / \mathrm{Kg}$. As per the globally harmonized system (GHS) if $\mathrm{LD}_{50}$ value is greater than the $2000 \mathrm{mg} / \mathrm{Kg}$ dose than the test product will be fallen under "category 5 " and toxicity rating will be "zero".

\section{Conclusion}

In this study locust bean gum grafted polyacrylamide has been successfully prepared. Various macromolecular characterizations confirm that graft copolymerization does take place. The optimum grafting was observed when the reaction mixture containing $20 \times 10^{-3} \mathrm{~mol} / \mathrm{L} \mathrm{KPS} ; 71.42 \mathrm{~g} / \mathrm{L}$ AAm and $7.14 \mathrm{~g} / \mathrm{L} \mathrm{LBG}$ was exposed to $800 \mathrm{~W}$ microwave power for $120 \mathrm{~s}$. We found that the swelling behavior of the graft copolymer is significantly influenced by the $\mathrm{pH}$ of the surrounding medium. The synthesized graft copolymer shows improved results for flocculation in comparison to its pure locust bean gum. Mice did not show any signs of toxicity or gross behavioral changes following acute oral administration of graft copolymer at $2000 \mathrm{mg} / \mathrm{Kg}$ body weight. No mortality was observed during 14 days after treatment with graft copolymer.

\section{References}

1. Dea, I. C. M., \& Morrison, A. (1975). Chemistry and Interactions of Seed Galactomannans. Advances in Carbohydrate Chemistry and Biochemistry, 31, 241-312. http://dx.doi.org/10.1016/ S0065-2318(08)60298-X.

2. Fernandes, P. B., Goncalves, M. P., \& Doublier, J. L. (1993). Influence of locust bean gum on the rheological properties of kappa-carrageenan systems in the vicinity of the gel point. Carbohydrate Polymers, 22(2), 99-106. http://dx.doi. org/10.1016/0144-8617(93)90072-C.

3. Glicksman, M. (1969). Gum technology in the food industry. New York: Academic Press.

4. Rojas-Argudo, C., del Rio, M. A., \& Pérez-Gao, M. B. (2009). Development and optimization of locust bean gum (LBG)-based edible coatings for postharvest storage of 'Fortune' mandarins. 
Postharvest Biology and Technology, 52(2), 227-234. http:// dx.doi.org/10.1016/j.postharvbio.2008.11.005.

5. Vijayaraghavan, C., Vasanthakumar, S., \& Ramakrishnan, A. (2008). In vitro and in vivo evaluation of locust bean gum and chitosan combination as a carrier for buccal drug delivery. Die Pharmazie, 63(5), 342-347. http://dx.doi.org/10.1691/ ph.2008.7139. PMid:18557416.

6. Maiti, S., Dey, P., Banik, A., Sa, B., Ray, S., \& Kaity, S. (2010). Tailoring of locust bean gum and development of hydrogel beads for controlled oral delivery of glipizide. Drug Delivery, 17(5), 288-300. http://dx.doi.org/10.3109/10717541003706265. PMid:20350054

7. Mohan, N., \& Nair, P. D. (2005). Novel porous, polysaccharide scaffolds for tissue engineering applications. Trends in Biomaterials and Artificial Organs, 18(2), 219-224. Retrieved from http://medind.nic.in/taa/t05/i2/taat05i2p219.pdf

8. Goni, I., Gurruchaga, M., Valero, M., \& Guzman, G. M. (1983). Graft polymerization of acrylic monomers onto starch fractions. I. Effect of reaction time on grafting methyl methacrylate onto amylose. Journal of Polymer Science: Polymer Chemistry Edition, 21(8), 2573-2580. http://dx.doi. org/10.1002/pol.1983.170210837.

9. Zohuriaan-Mehr, M. J. (2005). Advances in chitin and chitosan modification through graft copolymerization: a comprehensive review. Iranian Polymer Journal, 14(3), 235-265. Retrieved from http://journal.ippi.ac.ir/manuscripts/ipjE05140306.pdf

10. Kappe, C. O. (2004). Controlled microwave heating in modern organic synthesis. Angewandte Chemie International Edition, 43(46), 6250-6284. http://dx.doi.org/10.1002/anie.200400655. PMid: 15558676

11. Prasad, K., Mehta, G., Meena, R., \& Siddhanta, A. K. (2006). Hydrogel-forming agar-graft-PVP and $\kappa$-carrageenan-graftPVP blends: rapid synthesis and characterization. Journal of Applied Polymer Science, 102(4), 3654-3663. http://dx.doi. org/10.1002/app.24145.

12. Singh, V., Singh, S. K., \& Maurya, S. (2010). Microwave induced poly(acrylic acid) modification of Cassia javanica seed gum for efficient $\mathrm{Hg}(\mathrm{II})$ removal from solution. Chemical Engineering Journal, 160(1), 129-137. http://dx.doi.org/10.1016/j. cej.2010.03.020.

13. Sen, G., Singh, R. P., \& Pal, S. (2010). Microwave-initiated synthesis of polyacrylamide grafted sodium alginate: Synthesis and characterization. Journal of Applied Polymer Science, 115(1), 63-71. http://dx.doi.org/10.1002/app.30596.

14. Rani, P., Sen, G., Mishra, S., \& Jha, U. (2012). Microwave assisted synthesis of polyacrylamide grafted gum ghatti and its application as flocculant. Carbohydrate Polymers, 89(1), 275-281. http://dx.doi.org/10.1016/j.carbpol.2012.03.009. PMid:24750634

15. Yadav, M., Sand, A., \& Behari, K. (2012). Synthesis and properties of a water soluble graft (chitosan-g-2-acrylamidoglycolic acid) copolymer. International Journal of Biological Macromolecules, 50(5), 1306-1314. http://dx.doi.org/10.1016/j.ijbiomac.2012.03.010. PMid:22450052
16. Silva, D. A., Paula, R. C. M., \& Feitosa, J. P. A. (2007). Graft copolymerisation of acrylamide onto cashew gum. European Polymer Journal, 43(6), 2620-2629. http://dx.doi.org/10.1016/j. eurpolymj.2007.03.041.

17. Pal, S., Nasim, T., Patra, A., Ghosh, S., \& Panda, A. B. (2010). Microwave assisted synthesis of polyacrylamide grafted dextrin (Dxt-g-PAM): Development and application of a novel polymeric flocculant. International Journal of Biological Macromolecules, 47(5), 623-631. http://dx.doi.org/10.1016/j. ijbiomac.2010.08.009. PMid:20728467

18. Kaith, B. S., Jindal, R., Jana, A. K., \& Maiti, M. (2009). Characterization and evaluation of methyl methacrylate-acetylated Saccharum spontaneum L. graft copolymers prepared under microwave. Carbohydrate Polymers, 78(4), 987-996. http:// dx.doi.org/10.1016/j.carbpol.2009.07.036.

19. Singh, A. V., Nath, L. K., \& Guha, M. (2011). Microwave assisted synthesis and characterization of Phaseolus aconitifolius starch-g-acrylamide. Carbohydrate Polymers, 86(2), 872-876. http://dx.doi.org/10.1016/j.carbpol.2011.05.029.

20. Shah, S. B., Patel, C. P., \& Trivedi, H. C. (1994). Cericinduced grafting of ethyl-acrylate onto sodium alginate. Die Angewandte Makromolekulare Chemie, 214(1), 75-89. http:// dx.doi.org/10.1002/apmc.1994.052140108.

21. Deshmukh, S. R., Chaturvedi, P. N., \& Singh, R. P. (1985). The turbulent drag reduction by graft copolymers of guargum and polyacrylamide. Journal of Applied Polymer Science, 30(10), 4013-4018. http://dx.doi.org/10.1002/app.1985.070301005.

22. Sand, A., Yadav, M., Mishra, D. K., \& Behari, K. (2010). Modification of alginate by grafting of $\mathrm{N}$-vinyl-2-pyrrolidone and studies of physicochemical properties in terms of swelling capacity, metal-ion uptake and flocculation. Carbohydrate Polymers, 80(4), 1147-1154. http://dx.doi.org/10.1016/j. carbpol.2010.01.036.

23. Gils, P. S., Ray, D., \& Sahoo, P. K. (2009). Characteristics of xanthan gum-based biodegradable superporous hydrogel. International Journal of Biological Macromolecules, 45(4), 364-371. http://dx.doi.org/10.1016/j.ijbiomac.2009.07.007. PMid:19643130

24. Tako, M., Qi, Z.-Q., Yoza, E., \& Toyama, S. (1998). Synergistic interaction between $\kappa$-carrageenan isolated from Hypnea charoides Lamouroux and galactomannan on its gelation. Food Research International, 31(8), 543-548. http://dx.doi. org/10.1016/S0963-9969(99)00022-8.

Received: Apr. 07, 2014 Revised: Sept. 13, 2014 Accepted: Nov. 18, 2014 